\title{
Maternal HIV and drug use: effect on health and social morbidity
}

\author{
Jacqueline Y Q Mok, Amanda Ross, Gillian Raab, Barbara Hamilton, Sara Gilkison, \\ Frank D Johnstone
}

\begin{abstract}
A retrospective analysis of routine child health surveillance information was performed on health visitor records of 459 children, to examine the independent effects of maternal HIV infection and drug use during pregnancy on morbidity in the first 3 years of life. No significant differences were observed in the developmental progress of children born to HIV infected or drug using women when compared to community controls. The pattern of medical consultations in the first 18 months of life was significantly different, maternal drug use exerting a negative influence on outpatient visits (odds ratio $0 \cdot 6,95 \%$ confidence interval 0.4 to $1 \cdot 0)$. At 6 weeks, the majority of children lived with their birth parent(s), and no differences were observed between the groups. By 10 months of age, only $81 \%$ of children born to HIV infected drug using women lived with their parent(s). While maternal drug use and HIV did not have adverse effects on child health and development, these findings highlight the social implications for children affected by the heterosexual spread of HIV.

(Arch Dis Child 1996; 74: 210-214)
\end{abstract}

Keywords: maternal HIV, child health, drug use.

Maternal HIV infection per se has been found to have little impact on pregnancy outcome. ${ }^{1-4}$ In the western world, injecting drug users constitute the largest category of women with HIV infection. A prospective study of children born to women infected with HIV found that drug use during pregnancy exerted the most significant effect on birth weight. ${ }^{5}$

Illicit drug use is associated with medical and behavioural problems which cause adverse effects on pregnancy and infant outcome, independent of the pharmacological effects of drugs. Neonatal withdrawal symptoms are well documented, but the longer term consequences of in utero exposure to drugs are less well studied. Adverse outcomes could be attributable to less effective mothering by women who use drugs, or to suboptimal home environments. ${ }^{6-8}$

The independent effects of drug use and HIV infection on pregnancy outcome, infant development, and infant and child health have been difficult to ascertain. This is largely due to difficulties inherent in identifying and following up adequate numbers of drug using women with HIV infection, where the drop out rate is notoriously high. The lack of adequately chosen controls has also added to problems with data interpretation.

Few countries have a comprehensive health care system in the community, which allows systematic review of child health and development. Most areas in the United Kingdom do not have a problem with HIV and drug use as seen in Edinburgh..$^{9-11}$ The Edinburgh cohort comes from a well defined geographical area, where the HIV epidemic has been well studied. Follow up has involved hospital and community professionals, and together with the relative stability of the drug using population within Lothian, has resulted in an almost complete ascertainment.

This retrospective study was performed to examine pregnancy outcomes, child health and developmental status, and social morbidity in children of mothers associated with the drug using community, and compares the outcomes with children of community controls without these risk factors. The specific effect of HIV infection and drug use was investigated by comparisons within the group of cases, cross classified by these two risk factors.

\section{Methods}

IDENTIFICATION OF COHORT OF WOMEN HIV antibody testing became available in October 1985 and shortly after this the high prevalence of HIV in injecting drug users was reported. ${ }^{1011}$ Since then, women presenting for antenatal care have been specifically questioned about injection drug use by themselves or a sexual partner, with HIV testing readily offered where risk factors were identified. In addition there has been wide availability and acceptance of HIV testing in a number of sites throughout the city. This policy has meant a fairly complete recognition of HIV infected women who were pregnant.

Study children were born between 01.01 .83 and 31.12.92 to women who had an HIV test performed, and who reported either injecting drug use since 1982 or a drug using HIV infected partner, or both, as risk factors. Women who had drug using partners who were not infected with HIV were excluded from the study. The study database was built up from many sources, including two virus laboratories, the City Hospital HIV clinic, the antenatal clinic for drug users and HIV seropositive women, the City Hospital regional infectious diseases unit, other hospital departments, the community child health department, discussion with general practitioners and obstetric colleagues, and examination of all delivery 
Table 1 Characteristics of mothers and children

\begin{tabular}{|c|c|c|c|c|c|}
\hline & \multirow[b]{2}{*}{ Controls } & \multicolumn{2}{|c|}{$H I V$-ve mothers } & \multicolumn{2}{|c|}{ HIV + ve mothers } \\
\hline & & No drug use & Drug use & - No drug use & Drug use \\
\hline $\begin{array}{l}\text { No } \\
\text { Mother's age at delivery, years, mean (SD) } \\
\text { Boys, No (\%) } \\
<37 \text { Weeks' gestation, No (\%) } \\
\text { Birthweight <10 centile, No (\%) } \\
\text { SCBU, No (\%) } \\
\text { Withdrawal symptoms, No (\%) } \\
\text { Duration of follow up, years, mean (SD) }\end{array}$ & $\begin{array}{l}174 \\
23 \cdot 9(4 \cdot 5) \\
87(50) \\
22(13) \\
27(16) \\
11(6) \\
0 \\
3 \cdot 7(1 \cdot 4)\end{array}$ & $\begin{array}{l}107 \\
23 \cdot 2(4 \cdot 8) \\
63(59) \\
10(9) \\
16(15) \\
9(8) \\
3(2 \cdot 8) \\
3 \cdot 7(1 \cdot 4)\end{array}$ & $\begin{array}{l}86 \\
23 \cdot 9(4 \cdot 5) \\
51(59) \\
21(24) \\
12(14) \\
15(17) \\
10(12) \\
3 \cdot 7(2 \cdot 0)\end{array}$ & $\begin{array}{l}45 \\
22 \cdot 4(3 \cdot 6) \\
17(38) \\
3(7) \\
10(22) \\
3(7) \\
0 \\
4 \cdot 0(1 \cdot 3)\end{array}$ & $\begin{array}{l}39 \\
24 \cdot 8(4 \cdot 3) \\
17(45) \\
10(26) \\
10(26) \\
11(28) \\
9(23) \\
4 \cdot 0(1 \cdot 4)\end{array}$ \\
\hline
\end{tabular}

SCBU, admitted to special care baby unit; no drug use/drug use during pregnancy, as reported by the woman.

ward and operating theatre records. Great attention was paid not only to completeness of the record but also to very strict confidentiality. Data were held on disk, but without names or other identifiers. Elaborate care was taken with data storage and security.

\section{IDENTIFICATION OF CONTROLS}

Pregnancies were selected by individual matching of two controls to each case. Data for all Edinburgh city pregnant women were obtained from SMR1 maternity data and Scottish hospital inpatient statistics. The control women were matched to cases by age $(+/-5$ years), hospital of delivery, parity (one or more), ethnic group, smoking, year of delivery ( $+/-1$ year), and deprivation indices of postcode sectors, devised by Carstairs and Morris. ${ }^{12}$ Perusal of the case records from control pregnancies contained no evidence of HIV testing or drug use. Women in the control group were presumed HIV negative and nondrug users.

\section{FOLLOW UP OF CHILDREN}

All children were traced through the child health information systems for Lothian. The named health visitor was contacted for information available in the records collected during routine child health surveillance. No extra or special observations or examinations were required by the health visitors or school nurses. Reliance was placed on routine child health surveillance information collected at specified intervals, that is, from the notification visit, and checks at 6 weeks, 10 months, and 3 years. For preschool children, health visitor records were searched and data entry performed by the research assistant (questionnaire available on request). Records of school aged children were traced through the school health service and sent to a central point for data retrieval. Children who had moved away from Lothian were traced through community paediatricians for their area, who were asked to fill in a limited questionnaire on the child's health and development. Duration of follow up was calculated from the date of birth to the age at last entry in community nursing records.

\section{OUTCOME MEASURES}

From the child health records, the following information was sought.

\section{Developmental status}

Information was obtained for gross motor, vision and fine motor, hearing and speech, as well as social milestones. These were judged as normal or abnormal, as assessed by health visitor screening at around 6 weeks, 10 months, and 3 years.

\section{Outpatient episodes}

Outpatient episodes were obtained from the health visitor records, and coded by one observer (JM) without knowledge of the group of the child. Outpatient episodes included attendances at accident and emergency departments, and were classified as surgical, medical, developmental surveillance, or specialist referrals for developmental problems.

\section{Inpatient episodes}

Inpatient episodes were defined as those necessitating a stay of more than one day, with the principal diagnosis documented by the health visitor taken as the underlying cause for admission. Episodes were coded as follows: injury, social admissions, respiratory problems, gastrointestinal problems, other infections, elective surgery, and unspecified admissions. To avoid a disproportionate contribution from children with multiple episodes, the proportion of children who ever had outpatient or inpatient episodes was reported.

\section{STATISTICAL METHODS}

Logistic regression was used to identify the separate contributions of maternal HIV infection and drug use. This method summarises the data by expressing the logarithmic odds of the outcome as a linear function of explanatory variables. The jointly considered effects of maternal HIV infection and drug use were adjusted for parity, maternal age at delivery, smoking, and deprivation score.

\section{Results}

Of the 476 children identified, 17 could not be traced and the results presented relate to the 459 children on whom health visitor information was available. Thirteen children had died, at ages which ranged from $1 \cdot 1$ to 82 months. There were three deaths among community controls (two sudden infant death syndrome (SIDS); one myocardial infarction secondary to Kawasaki disease); three among 
Table 2 Developmental problems identified in children

\begin{tabular}{|c|c|c|c|}
\hline & \multicolumn{3}{|l|}{ Age } \\
\hline & 6 Weeks & 10 Months & 3 Years \\
\hline \multirow{3}{*}{$\begin{array}{l}\text { Community controls } \\
\text { HIV uninfected mothe } \\
\text { No drug use } \\
\text { Drug use } \\
\text { HIV infected mothers } \\
\text { No drug use } \\
\text { Drug use }\end{array}$} & $41 / 167(25)$ & $55 / 166(33)$ & $67 / 139(48$ \\
\hline & $\begin{array}{l}27 / 102(26) \\
23 / 75(31)\end{array}$ & $\begin{array}{l}30 / 99(30) \\
26 / 72(36)\end{array}$ & $\begin{array}{l}3(50) \\
(49)\end{array}$ \\
\hline & $\begin{array}{r}11 / 44(25) \\
9 / 38(24)\end{array}$ & $\begin{array}{l}15 / 44(34) \\
14 / 37(38)\end{array}$ & $\begin{array}{l}15 / 38(39) \\
14 / 33(42)\end{array}$ \\
\hline \multicolumn{4}{|c|}{$\begin{array}{l}\text { Figures represent } \frac{\text { Number with problems }}{\text { Number screened }},(\%) \text {. } \\
\text { No drug use/drug use during pregnancy, as reported by the } \\
\text { woman. } \\
\text { Odds ratios ( } 95 \% \text { confidence interval) at } 10 \text { months: } \\
\text { Maternal HIV } \\
\begin{array}{ll}\text { Drug use during pregnancy } \quad 1 \cdot 2(0 \cdot 7 \text { to } 2 \cdot 0), p=0.61 \\
1 \cdot 2(0.7 \text { to } 2 \cdot 1), p=0.45\end{array}\end{array}$} \\
\hline
\end{tabular}

children born to HIV infected drug using mothers (one Pneumocystis carinii pneumonia, one aspiration pneumonia, and one SIDS); one in a child born to an HIV infected woman who did not report drug use during pregnancy (HIV related cardiomyopathy); five in children born to HIV uninfected drug using women (one birth asphyxia, three SIDS, and one meningococcal septicaemia); and one death occurred in a child of a woman who was not infected with HIV and did not use drugs during pregnancy (intraventricular haemorrhage secondary to prematurity).

CHARACTERISTICS OF MOTHERS AND CHILDREN All mothers were white. The groups were comparable for maternal age at delivery and duration of follow up (table 1). More low birthweight infants were born to mothers with HIV infection, irrespective of whether drug use occurred during pregnancy $(p=0.04)$. Children born to mothers who used drugs during pregnancy were more likely to be admitted for special care $(p=0.003)$, or to have withdrawal symptoms reported $(p=0.0004)$.

\section{DEVELOPMENTAL PROGRESS}

During follow up, eight children were diagnosed as infected with HIV and were excluded from subsequent analysis, to avoid bias introduced by paediatric HIV infection. Very few children in any group were identified by the health visitors as having specific, pronounced, or long standing developmental problems. The results were therefore combined for any

Table 3 Medical consultations in first 18 months of life, controlling for maternal HIV infection and drug use during pregnancy

\begin{tabular}{|c|c|c|c|c|}
\hline & \multicolumn{2}{|c|}{ Maternal HIV infection } & \multicolumn{2}{|c|}{ Drug use during pregnancy } \\
\hline & OR $(95 \% C I)$ & $p$ & OR $(95 \% C I)$ & $p$ \\
\hline $\begin{array}{l}\text { Outpatient episodes } \\
\text { Any episode } \\
\text { Medical } \\
\text { Surgical }\end{array}$ & $\begin{array}{l}0.9(0.5 \text { to } 1.6) \\
1.0(0.5 \text { to } 2.0) \\
0.7(0.4 \text { to } 1.2)\end{array}$ & $\begin{array}{l}0.72 \\
0.98 \\
0 \cdot 20\end{array}$ & $\begin{array}{l}0.6(0.4 \text { to } 1.0) \\
0.5(0.3 \text { to } 0.99) \\
0.7(0.4 \text { to } 1.2)\end{array}$ & $\begin{array}{l}0 \cdot 06 \\
0 \cdot 04 \\
0 \cdot 21\end{array}$ \\
\hline $\begin{array}{l}\text { Any admission } \\
\text { Respiratory } \\
\text { Gastrointestinal } \\
\text { Injury/social } \\
\text { Other infections } \\
\text { Elective surgery }\end{array}$ & $\begin{array}{l}0.8(0.5 \text { to } 1.4) \\
2.0(0.9 \text { to } 4.2) \\
0.9(0.4 \text { to } 2.1) \\
1.7(0.8 \text { to } 3.5) \\
1.4(0.6 \text { to } 1.2) \\
2.5(0.9 \text { to } 7.0)\end{array}$ & $\begin{array}{l}0.44 \\
0.08 \\
0.77 \\
0.15 \\
0.42 \\
0.08\end{array}$ & $\begin{array}{l}1.0(0.6 \text { to } 1.6) \\
1.8(0.8 \text { to } 3.8) \\
0.9(0.4 \text { to } 2.0) \\
0.8(0.4 \text { to } 1.7) \\
0.9(0.4 \text { to } 2.0) \\
0.9(0.3 \text { to } 3.3)\end{array}$ & $\begin{array}{l}0.86 \\
0.13 \\
0.82 \\
0.59 \\
0.71 \\
0.15\end{array}$ \\
\hline
\end{tabular}

$\mathrm{OR}$, odds ratio; $\mathrm{CI}$, confidence interval. problems reported or identified during the defined window periods, and are outlined in table 2 . The estimated odds ratio was adjusted for case or control, parity, maternal age at delivery, smoking, and deprivation score. Neither HIV infection in the mother nor drug use during pregnancy had a significant influence on the child's development, with similar proportions of children in all groups identified as having delays. These were mild and involved hearing and speech as well as social milestones.

\section{MEDICAL CONSULTATIONS}

Because of the retrospective nature of data collection, non-specific information such as 'many visits' was excluded from analysis. Also excluded were attendances where the age was unspecified, and visits as part of research in the Edinburgh perinatal transmission study. ${ }^{13}$ The numbers of children who were ever seen as outpatients or who were admitted to hospital in the first 18 months of life were examined. Table 3 summarises the odds ratios for both outpatient and inpatient consultations. Significantly fewer children of drug using women had outpatient attendances for medical problems $(p=0.04)$. Although not statistically significant, infants of HIV infected women had a twofold increase in admissions for respiratory problems and elective surgery.

\section{CHILD CARE}

At 6 weeks of age, the majority of children lived with their parent(s). At 10 months, information on child care was available for 413 children, $393(95 \%)$ of whom were with their birth parent(s). However, only $81 \%$ of children born to HIV infected drug using women lived at home, with the odds ratio of living with the birth parent(s) reduced to 0.3 (table 4). Thirteen were living with grandparents or other relative, while seven were in foster care or had been adopted. Although many children had not reached 3 years or had been lost to follow up, maternal drug use and $\mathrm{HIV}$ infection continued to exert negative influences on child care.

\section{Discussion}

Children who are at high risk of perinatally acquired HIV infection are often also exposed to psychosocial factors which contribute to developmental delay and morbidity. Such factors include drug use in the mother, suboptimal antenatal care, perinatal events, and maternal ill health which compound erratic child care. Earlier studies documented neurodevelopmental impairment in infants born to HIV positive mothers who used intravenous drugs, but did not include appropriate controls. ${ }^{1415}$ More recent work has shown that prenatal exposure to HIV did not impede neurodevelopment, when no significant differences were found in the developmental performance of seroreverters when compared to children born to HIV uninfected women. ${ }^{16-18}$

Maternal drug use is associated with intrauterine growth retardation and neonatal 
Table 4 Children living with birth parent(s)

\begin{tabular}{|c|c|c|c|}
\hline & \multicolumn{3}{|l|}{ Age } \\
\hline & 6 Weeks & 10 Months & 3 Years \\
\hline \multirow{3}{*}{$\begin{array}{l}\text { Community controls } \\
\text { HIV uninfected mothers } \\
\text { No drug use } \\
\text { Drug use } \\
\text { HIV infected mothers } \\
\text { No drug use } \\
\text { Drug use }\end{array}$} & $165 / 165(100)$ & $159 / 162(98)$ & $129 / 133(97)$ \\
\hline & $\begin{array}{l}99 / 102(97) \\
71 / 75(95)\end{array}$ & $\begin{array}{l}95 / 98(97) \\
69 / 73(95)\end{array}$ & $\begin{array}{l}82 / 87(94) \\
52 / 60(87)\end{array}$ \\
\hline & $\begin{array}{l}44 / 44(100) \\
35 / 39(90)\end{array}$ & $\begin{array}{l}41 / 44(93) \\
29 / 36(81)\end{array}$ & $\begin{array}{l}35 / 40(88) \\
25 / 35(71)\end{array}$ \\
\hline \multicolumn{4}{|c|}{ Figures represent $\quad$ Number living with birth parents,$(\%)$. } \\
\hline \multicolumn{4}{|c|}{$\begin{array}{l}\text { Number of children with available information } \\
\text { No drug use/drug use during pregnancy, as reported by the woman. } \\
\text { Odds ratio ( } 95 \% \text { confidence interval) at } 10 \text { months: }\end{array}$} \\
\hline
\end{tabular}

withdrawal symptoms. ${ }^{6-8}$ The longer term effects on child development have been less well studied because of difficulties in unravelling effects related directly to the drugs from those caused by adverse social, environmental, and economic sequelae of addiction. A longitudinal study of 35 infants of drug dependent mothers in the Netherlands showed that at ages 4.5 and 5.5 years, $50 \%$ had lower scores in cognitive function when compared to controls, but a similar proportion of these children had been raised by someone other than their own parents. ${ }^{19}$

We have found that neither maternal HIV infection nor reported drug use during pregnancy exerted major influences on child health or development up to the age of 3 years. The study design, however, was retrospective and the information collected was dependent on health visitors' reporting of life events as well as episodes of contact with health professionals. By including community case matched controls, and ensuring data collection by one person, it was hoped that potential discrepancies would be minimised. Minor differences were found in the rate of medical consultations which are most probably explained by the inclusion of children born to HIV infected women in the Edinburgh perinatal transmission study to evaluate the risk of mother to child transmission of HIV. ${ }^{13}$ The close monitoring of these infants in the first 18 months of life may have accounted for the apparently fewer children seen in other outpatient clinics. On the other hand, maternal and medical anxiety have also resulted in an increased proportion of these children being admitted for respiratory problems, in case symptoms could represent Pneumocystis carinii pneumonia.

Information on outpatient attendances and hospital admissions was obtained from health visitor records, with no reference to International Classification of Diseases or Read coding. These episodes could be underreported and lead to a lower proportion of children who received medical attention. The accuracy of diagnosis could also be questioned. However, the inclusion of community controls and the coding of episodes by one person blinded to the groups of children should avoid detection bias.

With the maturing of the AIDS epidemic in Edinburgh an increasing number of women has become symptomatic with advanced HIV infection. Although the exact numbers of children who will be orphaned through AIDS are not known, it is predicted that for every 100 heterosexual adults infected with HIV there will be 60 dependent children. ${ }^{20}$ This is likely to be an underestimate of the problem, as not all HIV positive women will be identified in the antenatal period. Landesman et al showed that even in an area with a high HIV prevalence, $57 \%$ of seropositive women would have been detected, with an approach that targeted women with risk activities. ${ }^{21}$ Studies from Europe $^{22}$ and Africa have documented the high rates of parental mortality. Families in Kinshasa, Zaire, ${ }^{23} 24$ in which the mother was infected with HIV experienced a five- to 10fold increase in maternal, paternal and early childhood mortality compared to families where the mother was not infected. Morbidity rates in the uninfected children did not differ before and after the death of the mother, suggesting that maternal HIV infection did not compromise the standard of care received before the death of the mother. However, the presence of an extended family enabled continuity of child care, a factor which may not be available to many children in Edinburgh where maternal drug use may have alienated family members.

Our findings that neither maternal HIV infection nor drug use adversely affect the health and development of the children are encouraging. However, the stigma and secrecy surrounding HIV infection and drug use will compromise the standard of care received by the children. Increasing numbers of children are being placed in alternative care, and it remains to be seen if social services are adequately prepared or resourced to take on the growing problem of children orphaned through maternal AIDS or drug use. Longer term follow up will determine if these children will also require special educational provisions.

This study was supported by grants from the AIDS Virus Education Research Trust (AVERT), and the MRC (SPG9810211). We thank Miss E Alexander and Mrs I Vipond for facilitating the access to child health records, and the community medical and nursing staff for their cooperation.

1 Johnstone FD, MacCallum L, Brettle R, et al. Does infection with HIV affect the outcome of pregnancy? $B M^{-}$ 1988; 296: 467.

2 Selwyn PA, Schoenbaum EE, Davenny K, et al. Prospective study of human immunodeficiency virus infection and pregnancy outcomes in intravenous drug users. $\mathfrak{f} A M A$ pregnancy outcomes
$1989 ; 261: 1289-94$.

3 Minkoff HL, Henderson C, Mendez H, et al. Pregnancy outcomes among mothers infected with human immunodeficiency virus and uninfected control subjects. $A m \mathcal{J}$ Obstet Gynecol 1990; 163: 1598-604.

4 Maynard EC, Oh W, Indacochea F, Peter G. Human immunodeficiency virus infection and pregnancy outcome in intravenous drug users. Am $\mathcal{F}$ Dis Child 1990; 144: 1181-3.

5 Perinatal findings in children born to HIV-infected mothers. European Collaborative Study. Brf Obstet Gynaecol 1994; 101: 136-41.

6 Wilson GS, Desmond MM, Wait RB. Follow-up of methadone-treated and untreated narcotic-dependent methadone-treated and: untreated narcotic-dependent implications. F Pediatr 1991; 98: 716-22.

7 implications. F Pediatr 1991; 98: 716-22. and postnatal growth of children born to narcoticand postnatal growth of children born to
dependent women. $\mathcal{F}$ Pediatr 1983 ; 102: 686-91.

8 Wilson GS. Clinical studies of infants and children exposed prenatally to heroin. Ann N Y Acad Sci 1989; 562: prenatall
$183-94$.

9 Brettle RP, Bisset K, Burns S, et al. Human immunodeficiency virus and drug misuse: the Edinburgh experience. BMF 1987; 195: 421-4. 
10 Johnstone F, Hamilton B, Gore SM. Socio-economic factors associated with HIV infection in pregnant women. Health Bull (Edinb) 1992; 50: 156-62.

11 Robertson JR, Ronald PJM, Raab GM, et al. Deaths, HIV infection, abstinence, and other outcomes in a cohort of infection, abstinence, and other outcomes in a cohort of injecting drug $369-72$.

12 Carstairs V, Morris R. Deprivation and health in Scotland. Health Bull (Edin) 1990; 48: 162-75.

13 Mok JY, Hague RA, Yap PL, et al. Vertical transmission of HIV: a prospective study. Arch Dis Child 1989; 64: 1140-5.

14 Nozyce M, Diamond G, Belman A, et al. Neurodevelopmental impairments during infancy in offspring of IVDA and HIV seropositive mothers. Pediatr Res 1989; 25: 359.

15 Hittleman J, Willoughby A, Mendez H, et al. Neurodevelopmental outcome of perinatally acquired HIV infection in the first 15 months of life [abstr]. Program and abstracts, VIth International AIDS Conference, San Francisco, 1990: abstr SB200, 130

16 Aylward EH, Butz AM, Hutton N, Joyner ML, Vogelhut JW. Cognitive and motor development in infants at risk JW. Cognitive and motor development in infants at risk 146: $218-22$.

17 Wachtel RC, Tapper VJ, Houck DL, Nair P, Thompson C, Johnson JP. Neurodevelopment in pediatric HIVinfection: a prospective study. Pediatr AIDS HIV Infect 1993; 4: 198-203.
18 Nozyce M, Hittelman H, Muenz L, Durako SJ, Fischer ML, Willoughby A. Effect of perinatally acquired HIV infection on neurodevelopment in children during the first two years of life. Pediatrics 1994; 94: 883-91.

19 Van Baar AL, Soepatimi S, Gunning WB, Akkerhuis GW. Development after prenatal exposure to cocaine, Development after prenatal exposure to cocaine,
heroin and methadone. Acta Paediatr 1994; suppl 404: 40-6.

20 Ronald PJM, Robertson JR, Duncan BM, Thomson AS Children of parents infected with HIV in Lothian. $B M \mathcal{F}$ 1993; 306: 647-8.

21 Landesman S, Minkoff H, Holman S, McCalla S, Sijin O. Serosurvey of human immunodeficiency virus infection in parturients. Implications for human immunodeficiency virus testing programs of pregnant women. $\mathcal{F} A M A 1987$; 258: 2701-3.

22 Principi N, Fontane M, Marchisio P, Picco P, Massironi E, Tornaghi $R$. Changes in family structure of children born to HIV infected mothers. Pediatr AIDS HIV Infect 1992; 3: $15-18$.

23 Ryder RW, Nsuami M, Nsa W, et al. Mortality in HIV-1 seropositive women, their spouses and their newly born seropositive women, their spouses and their newly born
children during 36 months of follow-up in Kinshasa, Zaire. AIDS 1994; 8: 667-72.

24 Ryder RW, Kamenga M, Nkusu M, Batter V, Heyward WL. AIDS orphans in Kinshasa, Zaire: incidence and socio-economic consequences. AIDS 1994; 8: 673-9. 